\title{
QUALIDADE NA INDÚSTRIA AGROALIMENTAR: situação atual e perspectivas
}

\author{
José Carlos de Toledo \\ Professor Adjunto do Departamento de Engenharia de Produção e do Programa de Pós-Graduação em \\ Engenharia de Produção da Universidade Federal de São Carlos. \\ E-mail: toledo@power.ufscar.br \\ Mário Otávio Batalha \\ Professor Adjunto do Departamento de Engenharia de Produção e do Programa de Pós-Graduação em \\ Engenharia de Produção da Universidade Federal de São Carlos. \\ E-mail: dmob@power.ufscar.br \\ Daniel Capaldo Amaral \\ Doutorando do Programa de Pós-Graduação em Engenharia Mecânica da Escola de \\ Engenharia de São Carlos - USP.
}

\begin{abstract}
RESUMO
O objetivo principal do trabalho é identificar e discutir o estado atual da gestão da qualidade em empresas participantes de seis cadeias agroalimentares: bebidas (cerveja e refrigerante), biscoitos, carne bovina, chocolate, conservas de tomate e derivados do leite. Por tratar-se de estudo exploratório, foi adotado o método de pesquisa qualitativa de multicasos, envolvendo um total de 34 empresas. De modo geral, observou-se que, embora as empresas se encontrasse em diferentes estágios de gestão da qualidade, prevaleceram os enfoques em inspeção da qualidade e controle do processo, com ações de qualidade fortemente atreladas às exigências dos serviços governamentais de inspeção e de vigilância sanitária, com ênfase nos aspectos de sanidade do produto. Entretanto, existem indícios, ainda que localizados, de ações em direção a enfoques mais evoluídos, tais como sistemas de garantia da qualidade e gestão da qualidade total.
\end{abstract}

\section{ABSTRACT}

This paper aims to discuss quality management in six Brazilian agrifood chains: beverages (beer and soft drinks), biscuit, meat, chocolate, processed tomato and dairy. This work is a multi-case exploratory study among 34 firms in those agrifood chains. In a general sense, the firms studied are very different in terms of quality management. The control of the products or raw material for inspection, with special attention to satisfy the governmental health rules, is the most common situation. However, there are strong evidences that this general situation is changing. Several firms are going to employ more advanced systems in quality management (total quality management and quality assurance system).

PALAVRAS-CHAVE

Indústria agroalimentar, gestão da qualidade.

KEY WORDS

Agrifood chains, quality management. 


\section{INTRODUÇÃO}

Apesar da importância incontestável do setor agroalimentar para o país, o número de trabalhos que tratam da gestão da qualidade em tal setor é pouco expressivo. Os produtos agroalimentares são, literalmente, consumidos pelos clientes, de tal forma que a saúde deles pode ser seriamente comprometida em função da qualidade do produto. O poder público tende, portanto, a exercer um controle rigoroso sobre a qualidade final desse tipo de produto, por meio de normas de produção, distribuição e comercialização.

Assim, se, para alguns setores, a qualidade é uma vantagem competitiva importante, para as indústrias agroalimentares, ela é uma questão de sobrevivência. Um problema de não-qualidade, no caso extremo de um produto impróprio para o consumo humano, pode afetar de maneira importante a imagem de uma marca consolidada no mercado, comprometendo-a definitivamente. Dificilmente, um consumidor que viu sua saúde prejudicada pela ingestão de um produto deteriorado ou contaminado arriscaria novamente, se fosse possível evitar, comprar tal produto.

O objetivo deste estudo é identificar e analisar o estado atual e as perspectivas da gestão da qualidade em alguns segmentos (abate e processamento da carne bovina, biscoitos, cerveja e refrigerante, derivados do chocolate, derivados do leite, derivados do tomate) do setor agroalimentar brasileiro, com o propósito de, a partir da análise desse estudo inicial e levando em consideração as especificidades dessa indústria, desenvolver proposições gerais sobre a gestão da qualidade de tal indústria. Para tanto, foram entrevistadas 34 empresas representativas desses segmentos da produção agroalimentar.

\section{AGRIBUSINESS E QUALIDADE}

\section{Agribusiness e cadeia de produção agroindustrial}

Dois conjuntos de conceitos se sobressaem na formação da base teórica deste artigo: os apresentados na literatura sobre gestão da qualidade e os conceitos referentes ao agribusiness e sistema agroalimentar. Os conceitos sobre gestão da qualidade servem de base para o diagnóstico, possibilitando a identificação das variáveis de pesquisa a serem estudadas nas empresas. O ferramental teórico referente ao agribusiness e sistema agroalimentar, por sua vez, oferece a abordagem que deve ser utilizada para a aplicação dos conceitos sobre qualidade, por permitir uma análise abrangente e capaz de lidar com as especificidades dessa indústria.

Davis e Goldberg (1957) enunciaram o conceito de agribusiness como sendo "a soma das operações de produção e distribuição de suprimentos agrícolas, das operações de produção nas unidades agrícolas, do armazenamento, processamento e distribuição dos produtos agrícolas e itens produzidos a partir deles".

\section{OS PRODUTOS AGROALIMENTARES SÃO,}

LITERALMENTE, CONSUMIDOS PELOS

CLIENTES, DE TAL FORMA QUE A SAÚDE

DELES PODE SER SERIAMENTE

COMPROMETIDA EM FUNÇÃO DA

QUALIDADE DO PRODUTO.

Segundo esses autores, a agricultura não pode mais ser abordada de maneira indissociada dos outros agentes responsáveis por todas as atividades que garantem a produção, a transformação, a distribuição e o consumo de alimentos. Eles consideram as atividades agrícolas como fazendo parte de uma extensa rede de agentes econômicos que vão da produção de insumos até a transformação industrial, armazenagem e distribuição de produtos agrícolas e derivados.

O conceito de cadeia de produção agroindustrial utiliza a noção de sucessão de etapas produtivas, desde a produção de insumos até o produto acabado, como forma de orientar a construção de suas análises. Grosso modo, uma cadeia de produção agroindustrial pode ser segmentada, de jusante a montante, em três macrossegmentos. ${ }^{1}$ Em muitos casos práticos, os limites dessa divisão não são facilmente identificáveis. Além disso, essa divisão pode variar muito segundo o tipo de produto e o objetivo da análise. Os três macrossegmentos propostos são:

a) comercialização: representa as empresas que estão em contato com o cliente final da cadeia de produção e que viabilizam o consumo e o comércio dos produtos finais (supermercados, mercearias, restaurantes, cantinas, etc.);

b) industrialização: representa as empresas responsáveis pela transformação das matérias-primas em produtos finais destinados ao consumidor. O consumidor pode ser uma unidade familiar ou uma outra agroindústria;

c) produção de matérias-primas: reúne as empresas 
que fornecem as matérias-primas iniciais para que outras empresas avancem no processo de produção do produto final (agricultura, pecuária, piscicultura, etc.) (Batalha, 1997).

\section{Gestão da qualidade}

Adota-se o conceito de qualidade de produto como "uma propriedade síntese de múltiplos atributos do produto que determinam o grau de satisfação do cliente", conforme Toledo (1997). A qualidade de um produto pode ser avaliada por meio de um conjunto de características e parâmetros, específicos a cada caso, que são intrínsecos ou estão associados ao produto. Produto é entendido aqui como envolvendo o produto físico e o produto ampliado, ou seja, além do produto propriamente dito, envolve também a embalagem, a orientação para o uso, a imagem, os serviços pós-venda e outras características associadas ao produto.

A gestão da qualidade é entendida como a abordagem adotada e o conjunto de práticas utilizadas para obter-se, de forma eficiente e eficaz, a qualidade pretendida para o produto. A gestão da qualidade de uma empresa envolve seus processos e se estende aos fornecedores e clientes, segundo Toledo (1997).

Garvin (1992) considera que a gestão da qualidade evoluiu, ao longo deste século, em quatro estágios, os quais denomina de "eras" da qualidade e que são: inspeção, controle estatístico da qualidade, garantia da qualidade e gestão estratégica da qualidade.

a) inspeção: refere-se ao período em que a gestão da qualidade se limitava à inspeção dos produtos acabados. Trata-se de um enfoque meramente corretivo de inspeção do produto acabado, com o propósito de segregar as unidades não-conformes. De modo geral, as práticas adotadas não são baseadas em métodos científicos.

b) controle estatístico da qualidade: corresponde à era do desenvolvimento das ferramentas estatísticas de amostragem e de controle estatístico de processo, orientadas para o controle da qualidade no processo. O controle do processo é um enfoque preventivo centrado no acompanhamento e controle das variáveis do processo que podem influir na qualidade final do produto. Foi responsável por um grande salto nos padrões de qualidade da indústria e pela elevação do controle da qualidade ao status de disciplina científica.

c) garantia da qualidade: nessa era, a gestão da qualidade, de uma disciplina restrita ao chão de fábrica ou à produção fabril, assume um papel mais proeminente no gerenciamento da empresa. Deixa de ser apenas a aplicação de técnicas estatísti- cas para a prevenção e o controle da qualidade, assumindo o papel de garantir a qualidade em todas as áreas e atividades da empresa por meio de sistemas da qualidade. Os sistemas de garantia da qualidade estão associados a um enfoque relativamente mais amplo e preventivo, que procura, por meio de um gerenciamento sistêmico, garantir a qualidade em todas as etapas do ciclo do produto (da identificação das necessidades ao uso e descarte do produto).

d) gestão estratégica da qualidade: essa é a fase de evolução na qual a gestão da qualidade se encontraria atualmente, passando a ter uma dimensão estratégica. Nessa etapa, as empresas gerenciam a qualidade de forma proativa como fonte de vantagem competitiva, utilizando-se de um processo de planejamento estratégico para a qualidade e de um amplo conjunto de ações (programas, treinamento, grupos de melhoria, ferramentas de análise e melhoria de processos, qualidade no desenvolvimento do produto, etc.) para atingir os objetivos de satisfação total do cliente. Essa era se concretiza por meio da gestão da qualidade total, que se refere a uma visão de como gerenciar globalmente os negócios com uma visão orientada para a satisfação total do cliente e para a melhoria contínua. É composta por um conjunto integrado de princípios, ferramentas e metodologias que apóiam a melhoria contínua dos produtos e processos.

$\mathrm{Na}$ prática, o conjunto das empresas de um setor não se encontra num mesmo estágio de evolução com relação à gestão da qualidade. Algumas empresas podem apresentar enfoques e práticas relacionados com estágios mais avançados, como a garantia da qualidade e a gestão estratégica da qualidade, e outras empresas podem focalizar estágios menos avançados, restritos, por exemplo, à inspeção final dos produtos. No caso de empresas agroalimentares, elas também podem apresentar diferenças conforme a etapa da cadeia de produção em que se encontram, podendo haver etapas constituídas por empresas mais avançadas e etapas com empresas menos avançadas em relação à gestão da qualidade.

A gestão da qualidade no setor agroalimentar é condicionada pelas especificidades desse tipo de produto. O produto agroalimentar, em relação à sua qualidade, tem duas características marcantes. A primeira refere-se aos parâmetros e às exigências de qualidade que são ocultos, ou seja, aqueles que o consumidor não consegue detectar diretamente. Normalmente, esses parâmetros se encontram em normas e regulamentações oficiais e se referem aos padrões microbiológicos, à ausência de substâncias nocivas e 
à sanidade do produto em geral. Em relação a esses parâmetros, para a gestão da qualidade, é relevante o conhecimento sobre o que define a segurança para o produto em estudo e a aplicação da gestão da segurança e de ferramentas tais como Boas Práticas de Manufatura (BPM), Boas Práticas de Higiene (BPH) e Análise de Perigos e Pontos Críticos de Controle (APPCC).

A segunda característica do produto agroalimentar corresponde à importância dos padrões de qualidade de apresentação para a decisão de compra do produto. Assim, pode ser que um produto seja "perfeito" do ponto de vista da qualidade de segurança alimentar, mas o consumidor, a partir de sua percepção, não aprecie o produto e não deseje consumi-lo. Essa segunda característica se refere às propriedades sensoriais e de apresentação do produto, tais como sabor, forma, textura, praticidade, estética, embalagem, etc. Assim, para a gestão da qualidade, faz-se necessário avaliar a qualidade percebida pelo consumidor, identificar a qualidade esperada por ele e desdobrar os requisitos de qualidade do produto ao longo de toda a cadeia de produção e internamente à empresa em questão. Para tanto, são de grande relevância ferramentas como pesquisa de mercado, Desdobramento da Função Qualidade (QFD) e sistemas de garantia da qualidade.

Segurança e qualidade são duas dimensões inseparáveis em todas as fases da cadeia agroalimentar. A qualidade e a segurança de um alimento requerem mais do que regulamentações e ações de inspeção governamental. Segurança e qualidade dependem da cultura e do conhecimento de todos, ao longo da cadeia, para a prevenção e a prática da melhoria contínua, tendo em vista o consumidor final. É

Tabela 1 - Participação no valor total da produção alimentar brasileira

\begin{tabular}{l|c}
\hline Ramo de atividade & $\begin{array}{c}\text { Valor de produção em relação ao conjunto de } \\
\text { atividades da indústria alimentar brasileira (\%) }\end{array}$ \\
\hline Bebidas & 10,4 \\
\hline Cacau e derivados & 4,6 \\
\hline Carne e derivados & 17,5 \\
\hline Derivados de & 8,9 \\
\hline frutas e legumes & 8,9 \\
\hline Derivados do trigo & 10,2 \\
\hline Laticínios & 60,1 \\
\hline TOTAL & \\
\hline
\end{tabular}

Fonte: ABIA. O sistema e a indústria agroalimentar no Brasil. São Paulo : ABIA, 1993. fundamental, nas cadeias, o esforço voluntário e coordenado de identificação das causas dos problemas e a tomada de ações corretivas e preventivas pertinentes, ou seja, a gestão da qualidade em uma cadeia agroalimentar depende da participação consciente e voluntária de todos os envolvidos para que os ganhos sejam otimizados e usufruídos por todos. Isso depende da conscientização e da capacitação para a aplicação de boas práticas de manufatura e higiene em toda a cadeia.

Essas características demandam a coordenação de ações que influem na qualidade do produto final ao longo de toda a cadeia e também a conscientização de que a gestão da qualidade de uma unidade de produção deve transcender os seus limites.

\section{METODOLOGIA DE COLETA DE DADOS}

As cadeias agroalimentares pesquisadas são as seguintes: bebidas (cerveja e refrigerante), biscoitos, cacau e derivados, carne bovina, conservas de tomate e laticínios.

Essa escolha justifica-se, entre outras, pela importância dos ramos de atividades agroalimentares em que estão inseridas essas cadeias, se comparados ao conjunto da indústria alimentícia brasileira (Tabela 1).

É importante frisar que no interior dos ramos de atividade mencionados na Tabela 1 foram privilegiadas algumas cadeias de produção agroalimentares específicas. Assim, no setor de carne e derivados, foi focada a cadeia de abate e processamento da carne bovina; no setor de derivados do trigo, a produção de biscoitos; e, no setor de derivados de frutas e legumes, as conservas de tomate.

Para que os resultados da pesquisa de campo fossem representativos do conjunto das empresas agroalimentares dos setores abordados, a amostra analisada deveria refletir esse conjunto. Para atingir esse objetivo, a amostra de empresas foi estratificada primeiramente segundo a participação no mercado do segmento da cadeia em que as empresas atuam, de forma a obter-se uma amostra com a maior representatividade em termos de participação no mercado. Uma segunda estratificação foi considerada a partir do tamanho das empresas. Para efeito de simplificação e de adequação aos objetivos, as empresas foram agrupadas prioritariamente em dois blocos: "pequenas e médias" e "grandes" empresas. Além disso, dentro de cada estrato amostral foram priorizadas empresas que ocupassem diferentes posições na 
cadeia de produção agroalimentar (segmentação vertical) e empresas com origem de capital diferente (nacional e estrangeiro). A Tabela 2 apresenta a caracterização da amostra.

Para o levantamento de dados sobre o estado atual e as tendências de gestão da qualidade, foi elaborado um roteiro de entrevistas, o qual continha questões relativas aos seguintes temas: a) dados gerais das empresas; b) visão de qualidade predominante na empresa; c) sistema de gestão da qualidade existente; d) metodologias e ferramentas utilizadas para a gestão da qualidade; e) mecanismos de avaliação e resultados obtidos quanto à qualidade; f) tendências e perspectivas da gestão da qualidade; e g) principais dificuldades para a gestão da qualidade. Com os dados levantados, traçou-se um panorama geral sobre a gestão da qualidade nesse conjunto de empresas. Todas as 34 empresas da amostra foram visitadas, ocasião em que foi aplicado o roteiro de entrevistas. Normalmente, foram entrevistados o responsável pela gestão da qualidade na empresa e/ou o gerente de produção.

\section{GESTÃO DA QUALIDADE EM EMPRESAS DAS CADEIAS AGROALIMENTARES}

Essa seção apresenta os principais resultados da pesquisa de campo realizada nas cadeias agroalimentares estudadas.

\section{Gestão da qualidade na cadeia de produção de biscoitos}

O complexo agroalimentar do trigo envolve a produção, a transformação do grão de trigo e a sua distribuição na forma de farinhas, farelo, pães, massas e biscoitos. A indústria moageira, para atender à demanda interna, depende da importação do grão, já que a produção nacional de trigo é insuficiente.

Pôde-se observar que a empresa moageira estudada se encontra em estado razoavelmente avançado no que diz respeito à gestão da qualidade, adotando uma estratégia de garantia, e não apenas de controle da qualidade. Além disso, a empresa fundamenta e apóia sua gestão em um conjunto adequado de metodologias e ferramentas da qualidade. Apesar de adotar uma visão mais estratégica, a empresa ainda concebe a qualidade do produto como fortemente associada à conformidade com as especificações. E, embora evidencie preocupação concreta com a segurança do cliente, considera medianamente prioritária a sua satisfação, o que parece ser bastante contraditório.

Outro aspecto curioso refere-se ao fato de que, mesmo considerando problemático e crítico o controle de impurezas na matéria-prima que recebe, a empresa não se preocupa em implantar um programa para o desen-

Tabela 2 - Caracterização da amostra

\begin{tabular}{ll}
\multicolumn{1}{|c}{ Setores } \\
\hline Trigo \\
\hline Biscoitos \\
\hline Farinha \\
\hline Conservas de tomate \\
\hline Carne bovina \\
\hline Processamento \\
\hline Abate \\
\hline Laticínios \\
\hline Bebidas \\
\hline Cerveja \\
\hline Refrigerante \\
\hline Cacau \\
\hline Moagem \\
\hline Derivados \\
\hline Total \\
\hline
\end{tabular}

\begin{tabular}{|c|c|c|c|c|c|c|}
\hline \multirow[t]{2}{*}{ № de empresas } & \multicolumn{2}{|c|}{ Porte } & \multicolumn{2}{|c|}{ Capital } & \multicolumn{2}{|c|}{ Exportação } \\
\hline & Médio & Grande & Nacional & Estrangeiro & Sim & Não \\
\hline 4 & 2 & 2 & 3 & 1 & 1 & 3 \\
\hline 1 & 0 & 1 & 0 & 1 & 0 & 1 \\
\hline 6 & 1 & 5 & 5 & 1 & 4 & 2 \\
\hline 3 & 1 & 2 & 2 & 1 & 2 & 1 \\
\hline 2 & 1 & 1 & 1 & 1 & 0 & 2 \\
\hline 6 & 3 & 3 & 6 & 0 & 0 & 6 \\
\hline 3 & 1 & 2 & 3 & 0 & 1 & 2 \\
\hline 3 & 1 & 2 & 3 & 0 & 2 & 1 \\
\hline 4 & 0 & 4 & 0 & 4 & 4 & 0 \\
\hline 2 & 0 & 2 & 1 & 1 & 2 & 0 \\
\hline 34 & 10 & 24 & 24 & 10 & 16 & 18 \\
\hline
\end{tabular}


volvimento de seus fornecedores, revelando, assim, um controle da qualidade da matéria-prima ainda muito voltado para a situação de inspeção e análise.

É interessante salientar também que a empresa está sendo pressionada pelas exigências do mercado e que, diante da possibilidade de perder participação, ela se mostrou bastante flexível e disposta a se adequar às novas exigências, que é exatamente a forma como tem atendido um importante cliente, a Nestlé.

\section{O PODER PÚBLICO TENDE A}

\section{EXERCER UM CONTROLE RIGOROSO}

SOBRE A QUALIDADE FINAL DOS

PRODUTOS AGROALIMENTARES POR

MEIO DE NORMAS DE PRODUÇÃO, DISTRIBUIÇÃO E COMERCIALIZAÇÃO.

As empresas produtoras de biscoitos, de acordo com a amostra analisada, encontram-se em um estágio significativo de transição e de evolução da gestão da qualidade. Os dados coletados indicam que as práticas gerenciais adotadas nesse segmento (adoção de sistemas de garantia da qualidade, ferramentas e metodologias da qualidade total e técnicas de inspeção e avaliação) estão em estágio de evolução de abordagens ("eras") de gestão da qualidade fundamentalmente ligadas à inspeção de produtos para abordagens mais adiantadas, principalmente com a adoção de características das fases de garantia da qualidade e da gestão da qualidade total. Isso fica claro pelo fato de as práticas de inspeção e de controle do processo estarem consolidadas e, ao mesmo tempo, pelo fato de os esforços das empresas estarem direcionados para a adoção de estruturas organizacionais mais elaboradas para o gerenciamento da qualidade, da padronização de produtos e processos e dos programas de desenvolvimento de fornecedores.

Fica evidente também que, na opinião das empresas, a qualidade do segmento da farinha de trigo é o maior obstáculo para o desenvolvimento da qualidade dessa cadeia. Todas as empresas alegam sofrer no processo as conseqüências da baixa padronização dessa matéria-prima.

Por haver informações referentes a apenas uma empresa no setor de moagem, fica difícil tecer com- parações conclusivas entre os dois segmentos e traçar um retrato da cadeia de produção como um todo. Mas, avaliando-se que o moinho é uma empresa com conceitos e práticas desenvolvidos em gestão da qualidade, é difícil perceber onde está o problema revelado pelo segmento de biscoitos quanto à falta de padronização da farinha de trigo. Segundo os entrevistados do moinho, existem duas possibilidades. A primeira fundamenta-se na origem dos grãos, pois se acredita que o trigo brasileiro seja de baixa qualidade. A segunda diz respeito às condições de compra, uma vez que a empresa se vê obrigada a adquirir o grão de trigo com base nos resultados das suas análises, sem poder especificar as condições que ela realmente quer e das quais precisa.

Ao que tudo indica, a baixa qualidade da matéria-prima não seria fruto apenas da qualidade inferior do trigo nacional, mas também de problemas de qualidade na produção do segmento de moagem. Deve-se ressaltar que, no caso do moinho estudado, este dispõe de uma linha de produção específica (dedicada) ao segmento de biscoitos, o qual possui exigências maiores em relação à qualidade da farinha de trigo, o que não é comum em outras empresas moageiras.

\section{Gestão da qualidade na cadeia de conservas de tomate}

A cadeia de produção do tomate em conserva foi analisada em seu segmento de processamento industrial, por ser esse o elo que concentra praticamente toda a manipulação e todo o processamento do produto em conserva.

Três das empresas estudadas avaliam a qualidade de seus produtos segundo a visão de seus clientes diretos (supermercadistas e atacadistas). Para obter essas informações, utilizam seus representantes de vendas, os quais servem também como canal de reclamação desses tipos de clientes específicos. Uma quarta empresa utiliza-se de pesquisa de mercado, e uma outra utiliza indicadores específicos (vendas abaixo da meta para os supermercados e devoluções por tempo em estoque dos atacadistas). A sexta empresa utiliza continuamente um sistema de monitoramento do seu desempenho no mercado.

Quatro empresas realizam a avaliação dos seus produtos em relação à concorrência por meio de análises das características físico-químicas e organolépticas comparativas. Outras duas empresas realizam auditorias dos produtos em pontos-de-venda, avaliando-os também sensorialmente.

A tendência quanto à gestão da qualidade, em alguns aspectos, foi homogênea entre as empresas. Pra- 
ticamente todas citaram a automação, o lançamento de novos produtos e as melhorias em seus processos. Uma empresa foca sua atenção principalmente no acondicionamento do produto, adotando embalagens plásticas para a substituição dos tambores no transporte intermediário e a introdução da embalagem tetra-pak no produto final. Uma outra empresa se concentra no estudo do processo de acondicionamento asséptico. Também foram citadas, embora não de forma homogênea, a melhoria da capacitação dos recursos humanos e a existência de planos para a busca da certificação ISO 9000.

Um problema que afeta a melhoria da qualidade do produto de todas as empresas é o controle da matériaprima. Todas elas, sem exceção, citaram como problema o recebimento de produtos fora das especificações e fora dos prazos de entrega. Algumas incluíram o agravamento desse problema com as dificuldades de transporte e de estocagem da matéria-prima e uma citou também a distância dos fornecedores.

De maneira geral, as empresas desse setor têm práticas e políticas típicas de um estágio de gestão da qualidade da era da inspeção. Apenas uma empresa se destaca apresentando um sistema da qualidade mais evoluído, o que aparentemente lhe garante somente um maior nível de padronização. Além disso, as empresas parecem estagnadas quanto à gestão da qualidade, pois não têm, em geral, planos de adoção de novas práticas e ferramentas, ficando a tendência geral no setor circunscrita ao crescimento do nível de padronização e à elevação do grau de automação das unidades produtivas.

\section{Gestão da qualidade na cadeia de abate e processamento da carne bovina}

É crescente a conscientização do consumidor sobre a importância da qualidade dos produtos da cadeia da carne bovina. Além disso, o poder público está tentando estabelecer mecanismos que assegurem a qualidade do produto final, como, por exemplo, a exigência de que os cortes devem ser embalados para comercialização, a proibição da desossa no ponto-de-venda e o controle da rastreabilidade dos produtos finais.

Para essa cadeia, a análise restringiu-se ao segmento da industrialização, compreendendo aqui o abate e o processamento da carne.

De modo geral, um produto de qualidade para as empresas pesquisadas é aquele que atende às especificações técnicas e legislativas de consumo. Os principais fatores críticos apontados para a qualidade foram a questão do resfriamento (temperatura), a conservação, o processamento e também a matéria- prima. Assim, as empresas procuram controlar todo o seu processo produtivo, além de selecionar os melhores fornecedores, visando à qualidade final do seu produto.

Nas empresas do segmento de abate visitadas, não existem sistemas da qualidade implantados, e as ações da qualidade nessas empresas limitam-se às atividades de análises e controles laboratoriais. Exceto por uma única empresa, pode-se afirmar que, no segmento de processamento, existe uma maior preocupação com a adoção de programas da qualidade. Uma das empresas segue um programa da qualidade segundo o modelo de Crosby (1985), e a outra direciona a atuação mais para a conscientização e a mobilização dos funcionários para garantir a satisfação dos clientes. As atenções no setor estão voltadas para as novas tecnologias de criação do gado, o que pode garantir uma matéria-prima de melhor qualidade, e para novas tecnologias de processo. Em relação às tecnologias de processo, as empresas consideram sua maior barreira o aporte de capital para investimento.

Para as empresas de processamento, a melhoria e o desenvolvimento de novos produtos estão intimamente relacionados ao desenvolvimento de tecnologias de conservação das características organolépticas e nutricionais do produto.

No que tange aos fornecedores, os segmentos de abate e processamento também apresentam visões divergentes. As empresas de abate realizam apenas uma inspeção visual no gado, baseando-se na experiência profissional dos seus funcionários para detectar algum problema imediato. Na maioria dos casos, os problemas de não-conformidade da matéria-prima são detectados apenas depois do abate, na inspeção realizada pelos serviços de inspeção governamentais. A relação com os fornecedores segue critérios baseados na confiança adquirida em experiências anteriores. No caso das empresas de processamento, é realizada uma inspeção no recebimento, com análises microbiológicas e físico-químicas. Uma das empresas desse segmento possui um único fornecedor, que consiste, na verdade, em uma unidade da mesma empresa localizada em outro estado, para diminuir os custos com impostos. As outras duas têm uma relação de parceria com os fornecedores, mas afirmam enfrentar problemas quando necessitam de grandes quantidades de matéria-prima, pois não conseguem obtê-la de um único fornecedor, comprometendo assim a uniformidade do seu produto.

Quanto às metodologias e ferramentas, notou-se o uso, embora não oficial, do benchmarking com a finalidade de adaptar as inovações realizadas pelos concorrentes. Outras ferramentas unânimes nas empre- 
sas são as BPH e a inspeção por amostragem. As empresas de processamento, de uma forma geral, apresentam um conhecimento maior dessas ferramentas e utilizam ainda a APPCC e as BPM.

As empresas de processamento analisam os resultados obtidos quanto à gestão da qualidade de acordo com os índices laboratoriais para controlar o desempenho dos fornecedores, das matérias-primas, dos produtos em processo e dos produtos acabados. Para medir os índices de satisfação dos clientes, essas empresas utilizam serviços de atendimento ao consumidor. Já as empresas do segmento de abate avaliam seu desempenho por meio do volume de vendas, refletindo uma visão restrita sobre qualidade.

Um dos maiores problemas encontrados nessa cadeia é a falta de integração entre os atores envolvidos. Ao contrário do sistema agroalimentar do frango, no qual existe uma integração vertical das empresas ao longo de todo o sistema, desde a criação até a distribuição, na agroindústria da carne bovina, cada segmento da cadeia produtiva tem interesses próprios divergentes e com poucas perspectivas de coordenação geral.

\section{Gestão da qualidade na cadeia de leite e derivados}

A estrutura do complexo do leite é influenciada grandemente pelas características do produto e pela acirrada competição entre os produtores de seus diferentes derivados e outros produtos externos ao complexo. A amostra escolhida contemplou empresas de gestão privada e cooperativa, de portes diferenciados, que atuam em mercados regionais e nacionais, e produtoras de diferentes derivados do leite.

As informações coletadas indicam que a gestão da qualidade nas empresas do complexo do leite limitam-se às estruturas e práticas mínimas para o cumprimento das especificações controladas pelos organismos de inspeção governamentais. Isso fica evidente no fato de as empresas terem seus procedimentos de controle praticamente idênticos e fundamentalmente baseados nessas normas, sem demonstrar interesse ou tendência a adotar práticas mais elaboradas de gestão.

Esse fato torna-se ainda mais evidente quando se nota que, na própria visão de qualidade do produto, a preocupação das empresas, em muitos casos, recai sobre o fator custo. Três das empresas analisadas afirmaram que a satisfação do consumidor está fortemente associada com um produto de preço inferior. Portanto, essa visão de diferenciação por custos poderia ser a causa da estagnação, desviando as empresas de investimentos em gestão da qualidade. Essa afirma- ção é válida, obviamente, apenas para os produtos do complexo de menor sofisticação, aos quais o estudo se limitou. Uma outra visão predominante de qualidade em boa parte das empresas refere-se à manutenção da tradição da marca.

\section{A GESTÃO DA QUALIDADE É}

\section{ENTENDIDA COMO A ABORDAGEM}

\author{
ADOTADA E O CONJUNTO DE \\ PRÁTICAS UTILIZADAS PARA
}

OBTER-SE, DE FORMA EFICIENTE E

EFICAZ, A QUALIDADE PRETENDIDA

PARA O PRODUTO.

As seis empresas visitadas possuem estrutura de inspeção e laboratórios que atendem às exigências do Serviço e Inspeção Federal (SIF), duas delas possuem uma gerência que responde pela qualidade e nenhuma possui um sistema da qualidade formalizado. Quanto às ferramentas, metade das empresas não demonstrou sequer conhecê-las, e a outra metade está em processo de implantação das ferramentas BPM, BPH e APPCC.

Pode-se perceber que os problemas relacionados com o abastecimento e a qualidade da matéria-prima e os relacionados com a estrutura organizacional e com o modelo de gestão, principalmente no caso de cooperativas, representam as maiores barreiras a uma evolução em termos de gestão da qualidade das empresas. Outra dificuldade apontada diz respeito ao alto nível de defasagem tecnológica dos equipamentos instalados.

Em termos de tendências e perspectivas, as seis empresas enfatizam investimentos em melhoria no controle dos processos e na capacitação da mão-deobra.

\section{Gestão da qualidade nas cadeias de produção de cerveja e refrigerante}

Os dois produtos que mais se destacam em termos de quantidade de consumo na indústria brasileira de bebidas são a cerveja e o refrigerante. Esse fato orientou os esforços da pesquisa, que se concentrou nesses dois produtos. 
As três empresas produtoras de cerveja pesquisadas apresentaram características muito semelhantes em termos de gestão da qualidade. A visão de qualidade (padronização do produto e satisfação do cliente), as políticas, as inspeções (de recebimento, processo e expedição) e o enfoque bastante acentuado na padronização de produtos e processos são semelhantes em todas elas, revelando uma tendência de homogeneidade na gestão da qualidade nesse segmento. Outra característica que parece forte no setor é a

\section{PARA A GeSTÃo DA QUALIDADE,}

\section{É RELEVANTE O CONHECIMENTO}

SOBRE O QUE DEFINE A

SEGURANÇA PARA O PRODUTO

EM ESTUDO E A APLICAÇÃO DA

GESTÃO DA SEGURANÇA E

\section{DE FERRAMENTAS.}

importância atribuída a sistemas de garantia da qualidade (ISO 9000), a formas mais sofisticadas de avaliação das necessidades dos consumidores e à melhoria e ao lançamento de novos produtos. Uma das empresas já tem a certificação ISO 9000 e duas delas se encontram na fase final do processo de certificação. Todas dispõem de programas de qualidade assegurada dos fornecedores e de orientação e fiscalização dos pontos-de-venda.

Esse segmento encontra-se num estágio já de práticas condizentes com a era de garantia da qualidade, com a adoção de princípios adequados a essa era e de ferramentas tais como Controle Estatístico de Processo (CEP), APPCC, BPM, BPH, auditorias internas e benchmarking. As principais tendências apontadas são quanto à consolidação do sistema da qualidade ISO 9000, à adoção da ISO 14000 e à intensificação de treinamentos. A principal dificuldade apontada diz respeito à necessidade de constante adequação ao dinamismo e à forte concorrência nesse mercado.

O segmento final da cadeia de refrigerante, assim como o de cerveja, apresentou uma grande homogeneidade entre as empresas quanto à gestão da qualidade. Os resultados mostram também um direciona- mento para a padronização de produtos, processos e do sistema da qualidade, principalmente em termos da adoção das normas da ISO 9000, e para o desenvolvimento e aperfeiçoamento de produtos como estratégias para melhorar a qualidade. Todas dispõem de sistemas da qualidade formalizados, laboratórios de controle da qualidade e programas de qualidade assegurada de fornecedores. As formas de avaliação da matéria-prima e dos produtos em processo também são semelhantes. Benchmarking, BPH e BPM são apontados como ferramentas muito utilizadas.

As tendências em termos de gestão da qualidade são bastante divergentes entre as empresas. Os principais obstáculos para o desenvolvimento da gestão da qualidade nessas empresas dizem respeito às dificuldades para a obtenção de avanços na qualidade dos fornecedores e no grau já existente de controle do processo. Deve-se ressaltar que a amostra não contemplou o enorme contingente de pequenas empresas que atuam no mercado regional das chamadas tubaínas.

\section{Gestão da qualidade na cadeia de derivados do cacau}

A amostra foi formada pelas quatro grandes empresas do segmento de moagem do cacau (responsáveis por praticamente toda a produção brasileira) e duas dentre as três maiores produtoras de chocolate cobertura, as quais produzem em suas unidades também o chocolate destinado ao consumidor final.

Para todas as empresas do setor de moagem entrevistadas, de uma forma geral, um produto de qualidade é aquele que atende às especificações de características físico-químicas e de contaminação biológica e, além disso, que apresenta uniformidade nessas características. Existe uma ênfase forte na busca da padronização do produto final. Dentre essas características, as empresas priorizam o aspecto de contaminação microbiológica e higienização. Somente uma das empresas acrescentou a essa lista as características organolépticas dos produtos. As características demandadas nas matérias-primas são bastante homogêneas entre as empresas. Todas essas empresas destacaram a baixa qualidade do cacau brasileiro.

As empresas do segmento de chocolate cobertura e de derivados são menos homogêneas entre si com relação à visão da qualidade. Uma empresa centra sua visão de qualidade na busca de características técnicas do produto (granulometria, ponto de fusão, etc.). A outra empresa possui uma visão mais voltada para o cliente. As duas empresas citaram como aspectos mais importantes, que aumentariam a qualidade dos produtos e a satisfação dos clientes, o fortalecimento da imagem da marca e as melhorias na matéria-prima básica. 
De maneira geral, ambos os segmentos conhecem e aplicam, em maior ou menor grau, metodologias e ferramentas de gestão da qualidade. O segmento moageiro utiliza com maior freqüência essas ferramentas em relação ao segmento que o sucede. As empresas moageiras já têm implantadas ferramentas como amostragem, APPCC, BPM, BPH e estão em processo de implantação de CEP, Metodologia de Análise e Solução de Problemas (MASP), análise de valor e benchmarking. As empresas de moagem também se utilizam de medidas de desempenho em qualidade comuns entre si, tais como índice de reclamações dos clientes e índices de não-conformidades.

Em termos de tendências, pôde-se observar o interesse de todas as empresas pela utilização das normas de sistemas da qualidade e de gestão ambiental (séries 9000 e 14000). Duas empresas de moagem já possuem certificação ISO 9000, e as demais empresas de moagem e derivados estão com o sistema da qualidade ISO 9000 em processo de implantação. Três empresas de moagem pretendem implantar o sistema de gestão ambiental ISO 14000. As empresas de moagem também já dispõem de iniciativas de implantação de princípios e ferramentas da gestão da qualidade total. Pode-se dizer que o segmento de moagem possui uma gestão da qualidade mais homogênea, em estágio de garantia da qualidade e relativamente mais evoluído em comparação ao segmento posterior. De modo geral, todas as empresas da amostra possuem planos de intensificação dos níveis de automação.

Para o setor moageiro, os maiores obstáculos à evolução da gestão da qualidade são o relacionamento com os fornecedores e o gerenciamento da distribuição dos produtos. No segmento de chocolate cobertura e de derivados, os problemas com embalagem são uma dificuldade comum.

Não há nessa cadeia um padrão claro de tendências e dificuldades para a evolução da gestão da qualidade, tendo os resultados apresentado uma grande variabilidade entre as empresas. As normas de gestão da qualidade e de gestão ambiental, ISO 9000 e ISO 14000, parecem ser as mais adotadas, assim como as principais dificuldades parecem estar relacionadas com fornecedores.

\section{ANÁLISE E CONCLUSÕES GERAIS}

O estágio de evolução da gestão da qualidade variou entre as cadeias agroalimentares analisadas. A maioria delas, pelas práticas, estruturas e políticas demonstradas pelas empresas, enquadraria-se nas duas primeiras eras da gestão da qualidade, ou seja, a da inspeção e a do controle de processo ${ }^{2}$, o que implica uma abordagem fundamentada na inspeção ou a busca de maior controle do processo via técnicas mais apuradas como a aplicação de métodos estatísticos e de boas práticas de manufatura. É certo também que algumas delas, como a cadeia de biscoitos, a de moagem do cacau e a de bebidas, dão indícios de evolução em suas práticas de gestão da qualidade, enquanto outras parecem mais estagnadas, como, por exemplo, as cadeias de derivados do leite e da carne bovina.

\section{SEgURANÇA E QUALIDAdE SÃO}

\section{DUAS DIMENSÕES INSEPARÁVEIS}

\author{
EM TODAS AS FASES DA CADEIA
}

AGROALIMENTAR. ElAS DEPENDEM

DA CULTURA E DO CONHECIMENTO

DE TODOS PARA A PREVENÇÃO

\author{
E A PRÁTICA DA MELHORIA
}

CONTÍNUA, TENDO EM VISTA O

CONSUMIDOR FINAL.

Uma das especificidades da gestão da qualidade na indústria agroalimentar é o aspecto da segurança alimentar. Assim, a gestão da qualidade é, além de uma vantagem competitiva, uma exigência dentro desse setor econômico, e esse fato pôde muito bem ser observado nos dados colhidos nesta pesquisa, os quais mostram que todas as empresas consideram importante a inspeção de seus produtos e a padronização dos processos, existindo, no mínimo, uma estrutura de inspeção no recebimento de matérias-primas e durante o processamento e embarque do produto.

A pesquisa revelou que, de maneira geral, em todas as cadeias analisadas, a estrutura funcional responsável pelo gerenciamento da qualidade está associada a laboratórios de análise físico-química e microbiológica. Ficou evidente também a existência, ainda em termos gerais, de uma ênfase na padronização dos processos e na inspeção, mesmo havendo muitas empresas num estágio de esforço inicial nesse sentido. 
Verificou-se também, de forma geral, uma homogeneidade dentro de cada segmento quanto às formas de inspeção, pouca presença de práticas de gestão mais sofisticadas como as relativas às eras de garantia da qualidade e da gestão estratégica da qualidade e poucos indícios de que as práticas de gestão estão se movendo em direção a esse estágio. Isso demonstra que, apesar de as empresas agroalimentares brasileiras reconhecerem a importância da inspeção e da

\section{TODAS AS EMPRESAS CONSIDERAM}

\section{IMPORTANTE A INSPEÇÃO DE SEUS}

\section{PRODUTOS E A PADRONIZAÇÃO DOS}

PROCESSOS, EXISTINDO, NO MÍNIMO,

UMA ESTRUTURA DE INSPEÇÃO NO

RECEBIMENTO DE MATÉRIAS-PRIMAS

E DURANTE O PROCESSAMENTO E EMBARQUE DO PRODUTO.

padronização dos processos, pouco compreendem ou exploram a gestão da qualidade de maneira estratégica, ou seja, como forma de melhoria na competitividade da empresa por meio da satisfação dos clientes, diferenciando seus produtos no atributo qualidade. Isso pode ser demonstrado ainda pelas ferramentas e metodologias mais utilizadas, todas relacionadas com controle de processos e segurança alimentar (CEP, APPCC e sistemas de padronização), e pelas estruturas de avaliação da percepção da qualidade do produto pelo consumidor, as quais, de maneira geral, circunscrevem-se às informações obtidas via equipe de vendas e serviços de atendimento de reclamações de consumidores, evidenciando uma postura passiva.

Os dados mostram também que, quanto mais próximos do consumidor final, mais os segmentos apresentaram práticas de gestão, como inspeção e ensaios, menos homogêneas, estruturas mais elaboradas para avaliação da percepção do consumidor quanto à qualidade do produto e maior ênfase em aspectos organolépticos, como fica evidente, por exemplo, nas cadeias de biscoitos e de bebidas.

São comuns, em todos os segmentos analisados, problemas com relação ao controle e à padronização da matéria-prima. São exceções apenas as cadeias cujo setor precedente revela condições oligopolistas e produtos de maior complexidade técnica. Esse é o caso dos segmentos de produção da cerveja e do chocolate e derivados. Esses são os únicos segmentos analisados que não tinham a matéria-prima como uma das principais barreiras para a melhoria da qualidade no setor. Apesar de a matéria-prima ser comumente citada como obstáculo para a evolução da qualidade, parece que as empresas pouco vêm fazendo para mudar essa situação. Alguns exemplos de iniciativas para contornar esse problema foram observados no segmento final da cadeia de biscoitos, com a adoção de programas de desenvolvimento de fornecedores mais elaborados e medidas mais severas com eles, mas trata-se de exceções em meio à regra geral, em que se convive com a baixa qualidade dos fornecedores.

Quanto à avaliação da qualidade, as empresas recorrem, predominantemente, a inspeções no recebimento da matéria-prima e no processo, à sua estrutura de vendas e aos serviços de atendimento ao consumidor para medir o grau de satisfação dos clientes finais. Os grandes atacadistas e supermercados, inquiridos pelas equipes de venda, parecem ter um papel importante nesse processo de avaliação, sendo os mais consultados. Pôde-se perceber também que a técnica de pesquisa de mercado é bastante difundida nas cadeias agroalimentares, apesar de poucas empresas utilizarem-na regularmente.

As metodologias de apoio à gestão da qualidade são pouco difundidas. CEP, APPCC, sistemas de padronização (ISO 9000, BPM e BPH) são as metodologias mais conhecidas e utilizadas. Quanto à tendência de adoção, detectou-se uma heterogeneidade entre as cadeias e dentro delas. O grau pequeno de difusão das ferramentas para a gestão da qualidade no setor pode estar relacionado com o estágio de desenvolvimento dessa gestão em tal setor (ainda muito ligado às fases de inspeção e de controle do processo) e com a alegada baixa capacitação dos recursos humanos.

As tendências em termos de gestão da qualidade variaram bastante entre os setores. Há os que apresentam tendências claras como a automação (caso do segmento final de tomates em conserva e do segmento de moagem do cacau), os programas de qualidade total (cadeia de biscoitos) e as normas ISO 9000 (produção da cerveja e moagem do cacau), ao mesmo tempo em que persistiu uma grande heterogeneidade em outros itens. A única tendência que aparece frequientemente nas cadeias analisadas é a de valorização e de investimentos na capacitação dos recursos humanos e de padronização de produtos e processos. 
Em termos de dificuldades relativas à implementação da gestão da qualidade, o quadro se assemelha às tendências, com segmentos com dificuldades bastante comuns e outros mais heterogêneos em relação às dificuldades. O único caso é a matéria-prima, já citada, a qual é apontada como uma barreira para a evolução da qualidade em praticamente todos os segmentos analisados, principalmente os mais próximos do campo, como são os casos do leite, da carne bovina, do trigo e do tomate. Outras dificuldades citadas são relacionadas ao nível de capacitação da mão-de-obra, à capacidade de investimento e ao controle do processo.

A cadeia de produção de biscoitos se destacou pelos sinais de mudanças em termos de gestão da qualidade, ou seja, parece estar em um processo de evolução rumo a práticas avançadas de gestão. A cadeia da carne bovina, por sua vez, tem como grande especificidade o distanciamento entre os elos de abate e de processamento, no que tange aos aspectos de qualidade do produto. A cadeia do leite chama a atenção pelas dificuldades, grandes e variadas, enfrentadas pelas empresas, as quais vão desde a capacidade de investimento, passam por questões organizacionais e de gerenciamento e atingem até mesmo questões de ordem técnica próprias dessa agroindústria. A cadeia de produção do tomate em conserva chamou a atenção pela homogeneidade da gestão da qualidade nas empresas. Os segmentos finais da indústria de bebidas (cerveja e refrigerante) e de derivados do cacau destacam-se pelo alto grau de difusão dos sistemas de garantia da qualidade formais e de auditorias.

Não foram notadas diferenças significativas na gestão da qualidade em função do porte e da origem do capital, havendo, no geral, um nível um pouco maior de sofisticação nas inspeções ou na padronização nas empresas maiores.

Enfim, a pesquisa mostra que a gestão da qualidade na indústria agroalimentar brasileira ainda se en- contra voltada, fundamentalmente, para a inspeção e o controle do processo, de modo que ainda pode evoluir para formas mais sofisticadas de gestão, em que o fator qualidade se torna uma fonte de aumento da competitividade para as empresas. As empresas poderiam, portanto, seguindo esse rumo, atingir um desempenho melhor e diferenciar seus produtos na dimensão qualidade. Para tanto, precisam adotar estruturas organizacionais mais elaboradas para a função qualidade, sem perder de vista a importância da conscientização e da descentralização da responsabilidade pela qualidade, estabelecer políticas e programas da qualidade, adotar estruturas de mensuração da satisfação do cliente mais sofisticadas e, conforme a necessidade, utilizar mais metodologias e ferramentas de qualidade e aprimorar as já disponíveis.

Finalmente, vale destacar que os resultados demonstram que os organismos de inspeção governamentais, como o SIF, influenciam e desempenham papel importante na evolução da gestão da qualidade dentro das empresas agroalimentares. Ao que tudo indica, mudanças nas políticas e formas de ação desses organismos alterariam sobremaneira as estruturas de gestão da qualidade das empresas do setor. O estágio atual de gestão da qualidade identificado nas empresas foi, em grande parte, estruturado em resposta às exigências legais e às ações desses órgãos. Há, atualmente, planos de mudanças nas políticas e no papel dos órgãos, o que, caso venha a se concretizar, poderá alterar o panorama da gestão da qualidade nas cadeias agroalimentares. Assim, as mudanças previstas do papel da estrutura de fiscalização e vigilância sanitária nas empresas do setor, passando de atividades básicas de inspeção para a função de difusão e acompanhamento de programas e ações de gestão da qualidade, em direção a sistemas de gestão da qualidade total, poderão induzir e acelerar a evolução dos modelos de gestão da qualidade no setor. $\bigcirc$
BATALHA, M. 0. et al. Gestão agroindustrial. São Paulo : Atlas, 1997. vol. 1, cap. 1.

CROSBY, P. B. Qualidade é investimento. Rio de Janeiro : José Olympio, 1985
DAVIS, J. H., GOLDBERG, R. A. A concept of agribusiness. Boston: Harvard University, 1957. (Division of Research. Graduate School of Business Administration).
GARVIN, D. A. Gerenciando a qualidade. Rio de Janeiro Qualitymark, 1992.

TOLEDO, J. C. Gestão da qualidade na agroindústria. In: BATALHA, M. O. Gestão agroindustrial. São Paulo : Atlas, 1997. vol. 1, cap. 8. significa diminuir sua importância como fator indutor de mudanças na dinâmica de funcionamento do sistema agroindustrial como um todo.
2. 0 que, na nomenclatura de Garvin, corresponderia ao "controle estatístico da qualidade". 